\title{
"Strengthen the Nation": Exploring the Motivating Factors Leading to Irish Defence Forces Recruitment
}

\section{Mark Lennon.}

\begin{abstract}
Responding to a dearth of literature on the subject, this paper explores and examines what motivates people to join the Irish Defence Forces. In addition, it examines recruitment strategy and policy within the Defence Forces, in order to assess the degree to which this is appropriate to meet current needs. The paper explores the difficulties and challenges that all militaries currently face in attracting, enlisting, and retaining the required numbers of new recruits, with reference to current scholarship and to ideas relating to motivational theory. Analysis of the Irish case is based on a qualitative research design situated within an interpretive paradigm. Utilising a mixed methods methodology, data was collected through the use of focus groups, questionnaires and semi-structured interviews. Findings from this research indicate that themes such as pride, challenge and self- improvement appear to be strong motivating factors for recruitment. On the basis of this, a number of recommendations are suggested including key policy changes and resource investment that will assist the Defence Forces in addressing both the challenges of military recruitment both now and in the future.
\end{abstract}

It has often been said that the greatest asset of any military force is its people. This could certainly be applied to the Irish Defence Forces (DF) and is an opinion which has been reiterated on many occasions by both government and command figures within the DF. As an organisation with regular focus on recruitment and a requirement for young, motivated and enthusiastic personnel, it follows logically that recruitment and selection of the best, most suitable personnel, is significantly important for the DF. Not surprisingly, this view is corroborated repeatedly within current academic research in the Human Resource Management (HRM) field, which indicates that for organisations, critical success lies with the quality and availability of talent and human capital (Sparrow and Makram, 2015).

Globally, militaries are increasingly facing difficulties in attracting, enlisting, and retaining the required numbers of new recruits (Bachman et al, 2000; Knowles et al, 2002). Recruitment and retention have become a major concern, not just within the Irish DF. To attract and recruit the best possible people into an organisation such as the DF, therefore, requires a substantial HRM process ranging from advertisement to selection. At the foundation of this process, is an understanding of the motivation behind the application to 
join. Exactly what is currently motivating personnel to join the DF is not clear and a distinct lack of research exists in relation to this topic. Furthermore, little if any information exists within the organisation relating to this subject. Is patriotism a motivating factor for a potential soldier? Do personnel joining the DF have a sense of calling, a sense of vocation or a desire to serve their country, or are these particular factors more historic and applicable to other militaries? Are personnel motivated by the perceived benefits or the values of the organisation?

The problems facing the DF are further complicated by the findings of a recent climate survey, conducted within the DF by researchers from the University of Limerick, which suggests an organisation with low morale and one with many personnel, leadership and management issues (McMahon et al, 2017). This report, and other recent negative media reports on pay and conditions within the DF, do little in terms of potential recruit attraction and raise further questions on motivation to join. Thus, further research is warranted in this area of DF recruitment, prompting this research to examine why people join the DF and to understand the reasons and motivations behind that decision.

\section{Motivation to Join - The problem}

An understanding of an individual's motivation to join an organisation is particularly important given the fact that despite regular recruitment, at the end of 2017 the strength of the DF stood at an historic low of just under 9,000 personnel somewhat below the White Paper maintenance target of 9,500. With recruitment ongoing, it would be easy to assume that the DF target figure of 9,500 personnel will be reached quite easily and that no problems exist. However, in recent years due to a myriad of factors, predominately high employee turnover, this target figure has proved difficult to reach and maintain. General Service Competitions that took place in 2017, resulted in over 8,000 applications which represents substantial interest. However, fewer than 700 of these applicants were deemed suitable to be inducted as new entrants. The predominant factor here is that over half of the original applicants did not take part in the first stage of the selection process ${ }^{1}$.

While it can be argued that candidates are still being recruited, the figures do suggest that many applicants are not suited to the process and perhaps are being attracted for the wrong reasons. This, in tandem with the current demand requirement for recruits and the predicted forecast for increased demand in the future, allayed with an improving national economy, means that the problem is likely to be exasperated in the coming years. An analysis of this situation provides much food for thought. Are there fault lines or inefficiencies within the DF's recruitment strategy? Is there a necessity to examine candidates' original motivations to join in order to attempt to attract better suited personnel? Should the DF target specific personnel as part of their recruitment campaign? Can the DF attract more applicants? These are not easy questions to answer but an exploration of the factors affecting motivation to join and examining the theory behind that motivation, should lead to a better understanding of who is joining the organisation and why.

\footnotetext{
${ }^{1}$ As of May 2020 the strength of the DF was at 8485 personnel. 605 personnel were inducted into the DF in 2019.
} 


\section{Organisational Relevance}

The DF attracts a diverse range of recruits. As with all areas of employment, some recruits are stronger and better suited to the organisation than others. Identifying, quantifying and understanding the factors motivating these personnel to join and succeed in the organisation is something that would be hugely beneficial to the organisation. Achieving this task while acknowledging the vastness of the field of study, which dips into both sociology and psychology within an enhanced HRM sphere, is particularly challenging. However, by narrowing the focus into factors affecting motivation to join and examining the theory behind that motivation, benefit to the organisation should accrue. By understanding the underlying motivations encouraging young people to join the organisation, this paper can provide a useful roadmap for further refinement of the overall DF recruitment process and strategy for the future. In order for the DF to properly maintain its best asset, that is, its personnel, the organisation should aim to fully understand that asset, its origins and motivations.

\section{Aim and Scope}

This study offers an overview and analysis of the prime motivating factors leading to Irish Defence Forces recruitment and ultimately aims to answer the question of why people join. The intention is to contribute to the recruitment strategy of the DF, in order to assist with successful selection of suitable and motivated personnel. This research paper was conducted based on the understanding that a detailed development of occupational choice, such as incorporating research on civilians considering joining the DF, is beyond the scope of this research.

\section{Structure}

Part one of this paper will explore and consider the available literature on the reasons why people decide to join military organisations such as the DF, focusing in particular on the key concept of motivation and factors affecting motivation to join. During this literature review, a number of themes emerge which will feature throughout the remainder of the paper. Part two of this paper, outlines the research methodology and sets out the viewpoint, epistemology, and data collection techniques employed by the researcher. It also details the approaches taken while collecting and analysing the data and the rationale behind the decisions made. The penultimate section, discusses the concepts, themes and findings emerging from the research. The final part of the paper presents conclusions in the form of an overview of the factors influencing motivation to join the DF and provides a roadmap and suggested strategy for DF recruitment for the future.

\section{PART ONE. Literature Review.}

"Continuous recruitment is the lifeblood of the Defence Forces providing young, motivated and enthusiastic personnel to replenish military formations for operational deployments" (Department of Defence, 2015, p. 
75).

\section{Recruitment}

The topic of recruitment and its importance is reflected explicitly in the majority of HRM literature, indicating that for organisations critical success lies with the quality and availability of talent and human capital (Sparrow and Makram, 2015; Marchington et al, 2016). There are numerous definitions for recruitment within the literature. As defined by Weightman (2004), recruitment is the business of attracting sufficient candidates for a job at a reasonable cost. An additional institutional definition describes it as the process of having the right person, in the right place, at the right time (Chartered Institute of Personnel and Development, 2017). Finally, Armstrong (2012, p. 220) defines recruitment as "the process of finding and engaging the people the organisation needs". This is the most appropriate definition for this review, as the research will be predominately focussed on the individual and the organisation. As a renowned and respected HRM practitioner, Armstrong (2012) also lists ten stages of recruitment and selection that are applicable in understanding the concept of recruitment:

1. Defining requirements.

2. Attracting candidates.

3. Sifting applications.

4. Interviewing.

5. Testing.

6. Assessing candidates.

7. Obtaining references.

8. Checking applications.

9. Offering employment.

10. Following up.

The terms 'recruitment' and 'selection' are often used interchangeably. With reference to the above list, the first three points refer explicitly to recruitment; the remainder refer to the selection process. In simpler terms, recruitment is the phase that immediately precedes selection. The objective of the recruitment phase is to attract suitable candidates to proceed forward for the selection process (Rashimi, 2010). Other practitioners argue that the selection process is a subset of the recruitment process as a whole and that this only ends when a job offer is made and accepted (Torrington, Hall, and Taylor, 2005).

The following model (Figure 1), gives a simplified generic pictorial representation of the recruitment process. It allows for further understanding of the process as a whole: 


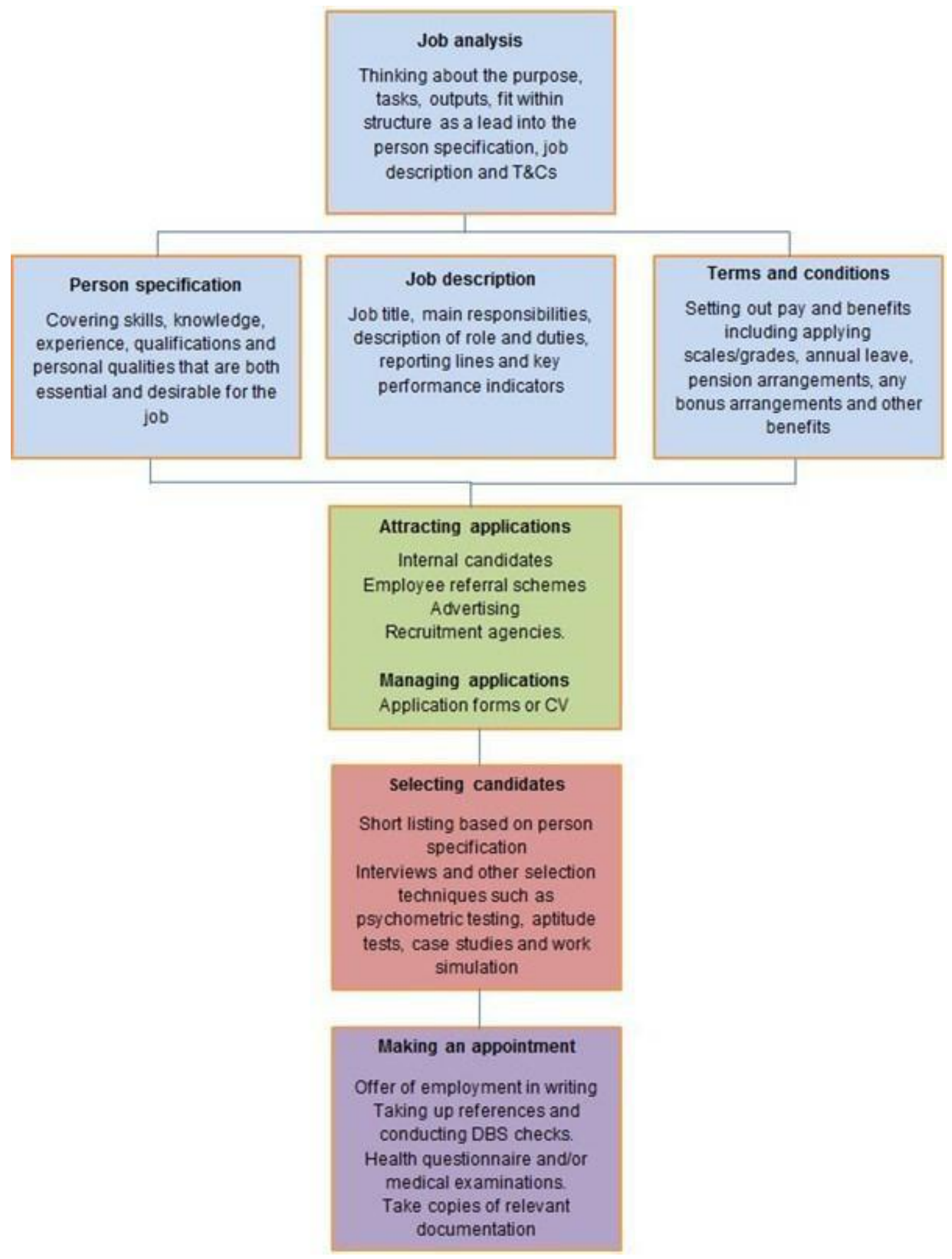

Figure 1: Recruitment Model (Chartered Institute of Internal Auditors, 2017).

The model above outlines five stages within the process: job analysis, job description which includes person specification and terms and conditions, attracting applicants, 
selecting applicants and finally making an appointment. The DF currently follows a similar model of recruitment as shown in Figure 2, below.

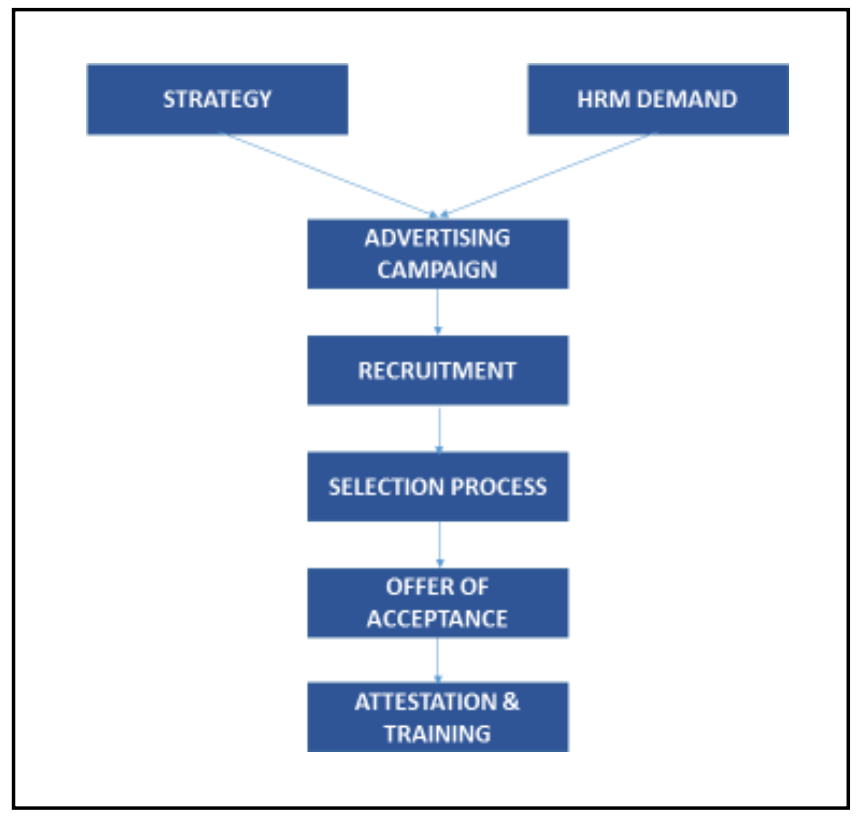

Figure 2: DF Model of Recruitment.

The above model illustrates a simplified version of the DF recruitment process. The strategy is dictated by government and DF policy and is normally set out in the government white paper or DF strategy statements. The strategy determines the numbers required in the forces (Department of Defence, 2015). The HRM demand is driven by the numbers of vacancies or positions available within the structure of the forces (Defence Forces Ireland, 2016). This leads to an advertising campaign being created and released to attract applicants, recruitment is conducted online and the selection process is started which includes a number of tests and an interview. If successful, a candidate will receive an offer of acceptance and the final stage, is attestation and commencement of training (Defence Forces Ireland, 2017). The process of DF recruitment is explained further in the following section.

\section{Defence Forces Recruitment}

Recruitment is the lifeblood of the DF as an organisation. Recruitment is highlighted and often central to many DF publications such as DF Strategy Statements, Annual Plans and Annual Reports. As mentioned in the DF Annual Report 2016 (Defence Forces Ireland, 2016b, p. 40), "recruitment takes place so as to maintain personnel numbers at or near the approved strength levels". Recruitment is certainly integral to the DF, particularly when considering the fact that the organisation cannot hire personnel directly into roles and positions given the specialist nature of training required (Defence Forces Ireland, 2016a). Recognising this importance, the DF uses a distinct, varied and thorough process to recruit personnel. This process allows for regular recruitment normally through a number of different strands: general service recruitment; apprentice recruitment; cadet recruitment for officer enlistment; and finally, direct enlistment of specialist trained personnel such as doctors, which occurs intermittently as required (Defence Forces Ireland, 2017).

In recent years, recruitment into the DF has remained constant even during the public 
service recruitment embargo. Recent recruitment campaigns have been successful in attracting large numbers of applicants, however as alluded to in the introduction, less than half of these applicants proceed to the first stage of the selection process (Williams, 2017). Moreover, little is known concerning candidates' underlying enlistment motivation, particularly at general service enlistment level. The process of general service recruitment and selection itself is dynamic and multifaceted. Advertisement of the recruiting competition takes place predominately on social media. Applications from interested personnel between the ages of 18 and 25, are submitted online and potential candidates are required to complete a psychometric test, a basic fitness test and a competency-based interview. During the interview, candidates are assessed under the following competencies: 'ability to work under pressure', 'teamwork', and 'motivation'. As part of the interview, candidates will be encouraged to give examples of when and where they have worked under pressure, had to apply and use teamwork and finally, when they had to demonstrate self-motivation to complete tasks. If they are successful in the above fitness and psychometric tests and interview, they are then required to pass a military medical examination as the final stage prior to being enlisted as a recruit (Defence Forces Ireland, 2017).

\section{Contemporary Challenges}

Recruitment in the DF and other militaries can and is being influenced by a number of factors. The United States (US) military recruits more personnel than any other global military force and requires over 100,000 enlistments annually (Philips, 2015). This recruiting challenge is further complicated by the high percentage of personnel pursuing third level education and the increased availability of civilian job opportunities (Eighmey, 2006). Militaries in many nations are increasingly facing challenges in attracting and recruiting the required numbers of personnel (Bachman et al., 2000; Knowles et al., 2002). Economic and demographic changes have reduced the recruit target pool and it is assessed, particularly from a US viewpoint, that there has been a decline in recruit quality since the early nineties (Asch, B; Du, C; Schonlau, 2004). Attention to what motivates youth to enlist in military service, that is, enlistment motivation, has been a longstanding aspect of policy formation and programme development for military recruitment (Eighmey, 2006). This has not been the case with Irish military recruitment policy but it is likely that enlistment motivation should be given greater consideration, taking into account the challenges that are currently in place, both with other international militaries and the DF organisation itself.

\section{Motivation Theory}

In order to fully understand enlistment motivation, the theory behind motivation itself must be explored. Motivation theory is a vast field which many academics have spent years attempting to analyse and explain. Even the definition of motivation often varies. Mitchell (1982, p. 81) presents motivation as "those psychological processes that cause arousal, direction and persistence of voluntary actions that are goal oriented." An additional definition presented describes motivation as the "inner force that impels human beings to behave in a variety of ways" (Tyson and York, 2000, p. 112). For the purpose of this research, motivation can be explained as the drive that influences people to behave or act in a certain way. The theory available on this subject is expansive. Traditional theorists such as Maslow and Herzberg have had their respective hierarchy of needs and dual-factor theory, applied to career motivation. Both are concerned with the individual and his or her motivational needs 
(Weightman, 2004).

Maslow's original hierarchy of needs concept has been adapted over the years but can still be used as a benchmark to understand human motivation and behaviour. Maslow identified five hierarchical levels: physiological, safety-security, belongingness, esteem, and self-actualisation (Maslow 1943; cited by Taormina and Gao, 2013). These range from, at the lowest level, satisfaction of basic physiological needs such as air, food and water to the highest level, satisfaction in terms of self-actualisation that is, achieving full personal potential and attaining self-fulfilment. In order to surmise why an individual would seek to join the military, Maslow's theory can be used as a simple tool to further understand these motives. A career in the DF could satisfy certain needs at a number of proposed hierarchical levels. However, Maslow's theory is not without criticism, in particular the assumption that individuals actually want to achieve "self-actualisation" and the perception that it is gender and culture biased (Taormina and Gao, 2013).

Herzberg's dual-factor model is somewhat related to the needs/content theory as proposed by Maslow above. The dual-factor model is based on Herzberg's study relating to job satisfaction and dissatisfaction labelling the satisfying events as "motivators" and the dissatisfying events as "hygiene factors". He applied this theory to job enrichment, where the motivators were linked to intrinsic factors such as recognition, personal growth, achievement and promotion and the hygiene factors were linked to extrinsic factors, such as salary, jobsecurity and working conditions (Herzberg 1959; cited by Sachau, 2007). Intrinsic motivation is defined as doing an activity for its inherent satisfactions, rather than for some separable consequence and often reflects a person's natural propensity to learn and assimilate. Extrinsic motivation is a construct that pertains whenever an activity is done in order to attain some separable outcome and often reflects an individual's dependence on instrumental value and external control (Ryan and Deci, 2000b). While Herzberg's theory has been repeatedly criticised in the literature, it nevertheless provides an appreciation of the dual nature of intrinsic and extrinsic motivation and could be useful in understanding and examining the motives that compel people to join the DF. Intrinsic motivation in terms of recognition, achievement, personal development and growth may be factors to consider when joining, as opposed to the extrinsic motivating factors of job security or pay. This is noteworthy, as people perform best and most creatively when they are intrinsically engaged in what they are doing (Csikszentmihalyi 1997; cited by Sheldon, Williams, and Joiner, 2003). On the other hand, it has been suggested that many people choose jobs on the basis of pay, location and reputation (Rynes, Bretz, and Gerhart, 1991).

A more contemporary theory of motivation is self-determination theory, which deals with a person's fundamental, innate need for competence, autonomy and relatedness, thereby motivating exploratory and growth-relevant behaviour. Simply put, people want to find things to do, and they want to do them well (Ryan and Deci, 2000a). In a follow on publication, it was presented that most people show considerable effort and commitment in their lives and that this appears to be more normative than exceptional, suggesting some very positive and persistent features of human nature (Ibid). While considering the above in terms of recruitment, it suggests that those who have displayed considerable effort and commitment in their actions in life will likely be self- determined and intrinsically motivated. Certainly, candidates with strong self- determination and intrinsic motivation would appear to more suitable to the military than those without this motivation (Sackett and Mavor, 2003). 
Other theorists such as Holland, propose that career choice is influenced by an individual's personality and fit to an occupation (Smith and Heinecken, 2014). This can be expanded further by exploring organisational values and how they may affect or attract potential candidates. People often seek jobs in organisations whose values fit their own and research shows that the weight of value information can influence job attraction (Research Task Group HFM-10, 2007). Another important contribution to the relevance of values for recruitment comes from Schneider's Attraction-Selection- Attrition (ASA) model (Schneider, 1995; cited by Research Task Group HFM-10, 2007). According to this model, people's preference towards an organisation depends largely on their estimation of the perceived fit, or compatibility between their personal characteristics and the organisational attributes or values. This is interesting in terms of DF recruitment. The DF as an organisation has a definitive set of inherent values; Respect, Loyalty, Selflessness, Physical Courage, Moral Courage and Integrity. These values are a foundation for the overall ethos of the organisation (Defence Forces Ireland, 2016a).

Expectancy theory can also be used to explore an individual's motivations to join an organisation. Vroom (1966) suggested that individuals are motivated by instrumentality (likelihood that job has certain attributes), valence (the attractiveness of those attributes) and expectancy (the individual's belief that they would be successful in the process). On a different slant, Gottfredson's (1981) circumscription and compromise theory, argues that career decisions are influenced by perceptions and image portrayed in relation to certain occupations. This can be determined by masculinity-femininity, occupational prestige, overall desirability and general field of work (Brown and Duane, 2002).

There are many more representations in the field of motivation but it is difficult to find a 'one size fits all' solution to aid our understanding of what makes people act and do. This can be rudimentarily explained by the fact that everyone is different. However, the underlying theory guides our understanding, particularly when viewed through the narrower lens of military enlistment motivation.

\section{International Military Research - Motives to join}

Within international military research, there are a number of studies covering this topic. Unfortunately, this research is predominately US based and there are few, if any, specific European studies or studies on militaries more reflective of the Irish DF. The motivating factors presented within the research are also somewhat varied. One particular US based study listed a number of factors ranging from altruistic motives as expressed in terms of duty, service, and patriotism, to motivations for self-improvement through increasing self-esteem and personal discipline while acquiring job skills, training and education (Woodruff, Kelty and Segal, 2006). The experiential aspects of adventure and desiring the rite of passage associated with military service are also cited, in addition to more pragmatic motives such as pay, benefits and a lack of other employment options. In a substantial publication by the US National Research Council (Sackett and Mavor, 2003), it was found that items such as an opportunity for adventure, a physical challenge and doing something to be proud of, were more powerful motivators than the external incentives such as pay and job security, somewhat echoing Herzberg's two factor 
theory on motivation. This study additionally highlighted the importance of parents (and particularly mothers) who it was observed have a critical influence on their sons' and daughters' career aspirations and achievements. This links positively with studies done in relation to women joining the DF, where two separate studies, cited below, identified the importance of parents and also other role models, such as career guidance teachers (CGT), as significantly important influencers on a young person's career aspiration. Also proposed within this study by the Research Council, is the effect that military service within the family can have on a young adult, that is, if one or both parents are currently working in the military or have previous military experience, it can lead to increased motivation for the son or daughter to join (Sackett and Mavor, 2003). This is also collaborated within studies on personnel in the Irish DF which are referred to later in this chapter.

A further study, based on a survey of potential recruits intending to join the US Army, identified six distinct enlistment motivational factors: "self-improvement, economic advancement, military service, time out, travel, and education money." (Pilske, Ellg, and Johnson, 1986, p. 19). This study also found that there are a variety of reasons behind the decision to enlist in the US Army both economic and non-economic and that different types of individuals, for example high school graduates versus non high school graduates and males versus females, are motivated to a certain extent by different reasons (Pilske et al., 1986). In a separate qualitative evaluation of reasons for enlisting in the military, it was found that a person's decision to join the military is complex and is commonly motivated by a number of factors. The following motivations underlying the recruits' enlistment decision were identified: having an historical interest, desire for self-improvement, opportunity to gain skills, job security, travel opportunities, and the opportunity to serve one's country (Ginexi, Miller, and Tarver,1995).

From examination of the literature, it appears that there are a number of tangible (extrinsic) and intangible (intrinsic) motivators which impact propensity to serve in the US military. Tangible motivators include salary, benefits, job security and money and intangible motivators include desire for self-improvement, desire to serve others, aspiration to serve one's country, and desire to become disciplined and confident (Woodruff, et al., 2006). Researchers exploring these motivations have often categorised these motives based on Moskos' Institution to Occupation model (Taylor, Clerkin, Ngaruiya and Velez, 2015). This model is useful in analysing and understanding the diverse individual level motivations about military service. According to the theory, the institutional military is one in which soldiers serve in response to a call to duty and patriotic desire to serve. In contrast, the occupational military is one in which the free market dominates military service and its members and soldiers join for a job and for the associated job benefits (Taylor et al., 2015). It has been posited however, in a study on recruitment to the South African military, that few people today choose a career purely due to its calling or due to other altruistic reasons, which require self-sacrifice (Smith and Heinecken, 2014).

Notwithstanding this, intrinsic motivation is often linked with Moskos' 'institutional orientation' whereas the 'occupational orientation' relates to the more extrinsic motivations of educational benefits, earning money, and receiving money as incentives to enlist. It could be argued that educational benefits are more intrinsic in nature as education lends itself to self- development and growth and self enhancement. 
Eighmey (2006) identified seven themes related to youth enlistment: benefits, fidelity (desire to serve community and duty to country), dignity (pride in work, working in environment free of discrimination), risk, family (approval/respect from family and friends), challenge, and adventure. He linked these themes with Moskov's model and although he suggests that the occupational variables (extrinsic values) have historically been used to draw in new military recruits, he and other scholars suggest that more research should be devoted to studying the institutional considerations (intrinsic values) that lead to enlistment decisions (Eighmey, 2006). In a separate US study on enlistment factors for student populations, it was found that students with fewer educational prospects after high school, have a higher propensity to enlist in the military. Conversely, individuals who performed well in high school and are children of college- educated parents are less likely to enlist (Segal and Segal, 2004).

\section{Why join the Irish Defence Forces (DF)?}

Since its inception as a state, Ireland has never imposed conscription and the decision to join the Irish DF is solely a voluntary one. As a small 'neutral' island nation, Ireland's military tradition and background is not very strong and perhaps as such, Irish society's relationship with the military is somewhat disconnected. So, what makes young Irish people decide to volunteer and join their own military force, the DF? Are there particular inherent motivating factors behind the decision to join?

In 2007, the Department of Defence, commissioned an independent market research company, TNS MRBI (2007), to examine the Retention and Recruitment of Women in the Defence Forces. This research was intended to identify areas where action could be taken to increase the number of women applicants to the Defence Forces. Although the report was fundamentally focussed on female participation, there are many informative elements. It is also one of the only independent studies that has been conducted, that includes an exploration into factors affecting the motivation to join the DF. It included a quantitative survey of over 500 female personnel and a qualitative survey of career guidance teachers (CGT) and parents, among others. Some of the perceived attractions to the military cited were: the physically active, adventurous nature of the job combined with the use of new equipment, a perceived tight knit community of colleagues with a sense of camaraderie, a permanent career, a perceived status and a sense of national pride. This resonates with the findings of international research outlined above (Woodruff et al., 2006; Eighmey 2006; Ginexi et al., 1995). Additionally, a number of factors were identified as further motives to joining. These included having a history of military tradition in the family, having friends in the DF and residing close to a military base as people were increasingly familiar with the roles of the DF (TNS MRBI, 2007). This report also pointed to the importance of the role of parents and CGTs in facilitating career aspirations.

In a recent exploration on the role of gender in the DF, among the main factors highlighted motivating women to join were the challenge, education and adventure opportunities available within the organisation and that these opportunities had a strong relationship with fitness and sport. (Clear, 2017). In a separate study related to DF targeted female recruitment, sport and team-work was again highlighted as an important area of interest and additionally the influence of significant others or "gatekeepers" who were identified as important motivators (Egerton, 2016). This aspect concerning the importance of 
gatekeepers is linked with the TNS MRBI (2007) report, where parents and CGT were identified as important career decision facilitators who need to be informed. This was also highlighted within international research (Sackett and Mavor, 2003). Aside from these specific studies, which are limited due to their gender focus or application, there appears to be a lack of defined research into motivation to join the Irish Defence Forces.

As alluded to in the introduction of this paper, the DF's lifeblood is its personnel. The ability to attract the right quantity and quality of human resources remains a critical aspect for the organisation. In assessing and analysing the theory it is evident that there are many different factors involved in why people are motivated to join the military. Themes have emerged from this review. Firstly, from motivational theory, it appears that intrinsic and value led motivation appears to be a greater motivator or attractor to the military than extrinsic or more tangible motivators. Secondly, it is clear that parents and influencers within a young adult's life play a key role in their decision making. Thirdly, factors such as adventure, pride, challenge and self-improvement appear to be motives for many to join. Finally, and interestingly when narrowed to the DF, the role of sport and fitness also appears to be a strong motivating factor. These themes will be developed further in the remainder of the paper.

\section{PART TWO. Methodology}

This research used both quantitative and qualitative methods of data gathering. The sample, which was purposive and criterion based, established the views and experiences of newly enlisted recruits with less than six months experience in the DF. All participants in the study were invited to complete the questionnaire. Focus groups were conducted with selected personnel in two separate locations. Semi-structured interviews were conducted with military officers involved in recruitment within the DF. Further interviews were conducted with a civilian HRM academic and two secondary school career guidance teachers (CGT).

This research used purposive sampling with criterion, as the sample participants had to meet the criteria of being newly inducted recruits with less than six months experience (Cohen et al., 2011). All participants were undergoing induction training at the time this research was conducted. Purposive sampling is the selection of 'information-rich cases' from which one can learn about issues of central importance to the purpose of the research (Patton, 2001). Question focus was mainly on the area of motivation to join, factors influencing this decision, job attractiveness and perceived organisational benefits and values. The criteria above were set in order to ensure that participants were able to recall their true reasons for joining.

\section{Questionnaire}

In order to ensure content validity, the questionnaire was piloted before administration. Initial samples of questionnaires were given out as a trial to peers, to develop the questions and get feedback on the survey. Careful consideration was afforded to the formation of the questions. Piloting ensured that the "wording of the questions" was coherent and explicit and "accessible to everyone within the intended population" (Armour and McDonald, 2012, p. 101). Many different scales were exploited in the development of the questionnaire which allowed for more comprehensive answering, for example: rating scale, rank ordering, multiple choice and open-ended questions (Cohen et al., 2011). 
Questionnaires are predominantly used as a quantitative research tool. Closed questioning is the most common form but open-ended questions were employed in the questionnaire to ascertain the personal views of participants regarding their motivation to join. Open-ended questions allow participants to deliver more information and a personal touch which adds honesty, richness and authenticity that are at the core of qualitative data (Cohen et al., 2011). The disadvantage, conversely, is that they can "be difficult to answer and more difficult to analyse" (Opie, 2004, p. 107). The design of the questionnaire was short and concise in order to "reduce the risk of respondent fatigue," and a clear, "easy to follow" questionnaire was provided thus reducing the chance that participants "fail to follow filter questions" or "inadvertently omit a question" (Bryman and Bell, 2007). Questionnaires were distributed following contact with the individual training institutions, in the three separate geographical areas. Commanders at each location facilitated the researcher with dedicated off-programme time, to brief and introduce the questionnaire.

As a result of conducting the questionnaire within the group military environment and having dedicated time with a "captive" audience, the participation rate was particularly high resulting in 123 completed questionnaires from a possible 142 personnel.

\section{Focus Groups}

Focus groups are often described as loosely constructed discussion groups, with participants brought together for the purpose of the study who are then guided through a series of topics or questions by the researcher (Sarantakos, 2005). Focus groups were selected because they can be utilised to generate qualitative data and allow participants to discuss and comment on their own personal experiences, related to the topic of this study, that is, motivation to join the DF. A focus group is also more likely to facilitate the elicitation of a wide variety of different views and will allow individuals within the group to challenge each other's views (Bryman, 2008). Participants for the focus groups were selected randomly on a volunteer basis from the sample who completed the questionnaire.

\section{Semi-Structured Interviews}

By way of triangulation, a number of semi-structured interviews were conducted. Triangulation is defined as "the use of two or more methods of data collection in the study of some aspect of human behaviour" (Cohen et al., 2011, p.112). Semi-structured interviews permit the use of pre-determined yet open-ended and fluid questions in a conversational manner, facilitating the flexibility required to probe points identified during individual interviews (Yin, 2009). The interview questions were constructed to link the themes and concepts that arose from the questionnaire and focus group research, while remaining true to the requirements of the research question. Patton (2001) asserts that the purpose of interviews is to gain an appreciation of another person's views and elicit information that we cannot observe such as feelings, experiences, thoughts and concerns. Bevan (2014) claims that the insight gained from well conducted interviews, provides the key element of the phenomenological approach.

The semi-structured interview allows the interviewer to develop and use an interview 
guide, or a list of questions and topics that need to be covered during the conversation, usually in a particular order. The interviewer follows the guide, but does not have to stick rigidly to it. Using semi-structured interviews based on the shared understanding model of data collection, allows the interviewer to pursue lines of thinking introduced by the interviewee, encouraging $\mathrm{him} /$ her to offer new meanings or insights on the subject field. (Walsh and Ryan, 2015). This type of interview was deemed the most appropriate for the research as it allowed the researcher to keep an open mind and guide conversations (Yin, 2009).

\section{Data Analysis}

An analysis of the individual questionnaires allowed for reflection on arising themes and identification of emerging patterns. In some cases, it was possible to link these themes with those identified within the literature examined earlier. These themes and patterns allowed for further refinement of the semi-structured interview questions. With both the questionnaire and focus groups, a rich summary of the participants' rationale and motivation to join was captured through examining emerging patterns and codifying similar contributions into themes. These themes, although somewhat different in application, were further explored and evaluated in the subsequent interviews with DF officers.

\section{Ethical Considerations}

Conscious of the often times robust nature of training within the DF and how rank may intimidate inexperienced recruits, the research approach, while exploratory in nature, was conducted in a relaxed and informal manner. Maynooth University research ethics policy document (2016) was used as a guideline for all ethical considerations. Mindful of this perceived rank and authority issue, the focus group method was deemed particularly important as participant's personal reflections were more likely to be revealed in focus groups rather than in a traditional one on one interview, dominated by the authority of the researcher (Bryman, 2008). Participants were part of a purposive, criterion sample but participation in both the questionnaire and focus groups was voluntary in nature. Participants, at questionnaire and focus group level, were informed about the purpose of the research and that anonymity would be used to allow for freedom of expression. Participants, involved in interviews, were also informed of the purpose of the research, the option of anonymity, the right of participants to decline to be interviewed and the opportunity to review and correct comments attributed to them prior to publication. This style of research approach facilitated the development of trust and confidence with the interviewees.

\section{PART 3. Findings.}

The purpose of this paper is to explore a person's underlying motivation to join the DF as a general service recruit and to identify factors that influenced that decision to join. The findings from the data, obtained from both the questionnaires and focus groups, centre mainly on this research question. A secondary aim of the research was to examine the overarching DF recruitment strategy and policy, and this was addressed mainly through the findings from semi-structured interviews. Both aspects are discussed below, along with an analysis of the categories, concepts and themes arising from the research as a whole. 


\section{Questionnaire and Focus Group Participant Demographics}

123 questionnaires were completed at three separate training locations. The participants were predominately male, with just under nine percent female. This is somewhat reflective of the current gender demographic in the DF, which is six percent female. Two focus groups were conducted, with eight male participants in one group and nine participants in the other group, including two females. The gender issue was not explored in this particular study. In any case, on analysis there were no discernible differences between the responses of the female participants, compared with their male counterparts, from either the questionnaire or focus group data. The participants ranged in age from 18-26 years of age, but were predominately in the 20-23, year old bracket. They come from a wide geographical spread of over 20 counties with the majority of participants from Kildare, Dublin, Donegal and Westmeath. These four counties all have military barrack installations. Living close to these installations and being aware of the DF presence are potentially influencing factors for recruitment. Certainly, as will be shown later, having friends or family in the DF, is a strong influencing factor which may also be linked to the majority representations of the counties above.

On a separate note, there were three non-nationals surveyed from within the sample group, who originated from Moldova, Lithuania and Poland. Interestingly, their responses did not vary significantly from the majority of the sample. There were a number of participants from Northern Ireland. A theme of pride in the national flag emerged as an attraction and a reason to join amongst this particular demographic. Otherwise, there were no other discernible or significant demographic differences.

The vast majority of personnel, 95 per cent, have completed Leaving Cert level education ${ }^{2}$, with a minority holding further education up to degree and even post- graduate degree level. The minimum educational standard attained was Junior Cert level. Interestingly and surprisingly, only four per cent of the sample participants joined the DF directly from school. The vast majority were already in the workforce in varied job specifications, reflecting the sample age demographic bracket of 20-23, year olds. This significant finding strongly suggests that more can be done in terms of focussed DF recruitment within schools, with the primary aim of targeting and recruiting school leavers.

\section{Motivation to Join}

The data gained from both the quantitative and qualitative aspects of this research, suggests a number of varied reasons and motivations behind the decision to join the Irish DF. This mirrors the academic research as explored in the literature review, where a variety of factors and motivations were given as reasons for joining the military (Woodruff, et al., 2006; Ginexi, et al., 1995; Pilske et al., 2006). Nonetheless, three distinct themes emerge from the findings in relation to motivation to join. These themes are identified as follows:

a. Pride; both personal and occupational.

b. Challenge, that is, the challenge that life in the DF brings.

\footnotetext{
${ }^{2}$ The Leaving Certificate is the qualification taken by Irish students before they leave Secondary School, usually at c. 18 years old. It is broadly equivalent to the UK 'A' Levels or the US Advanced Placement courses. Junior Cert is roughly equivalent to the UK GCSE exam, taken at c.16 years old.
} 
c. Self-improvement, that is, the ability to improve oneself and reach full potential, both physically and mentally.

A number of other motives also emerge strongly from the findings. These are; camaraderie, gaining friends for life, being part of a team and having the ability to enter a long-term career.

\section{Thematic analysis - Main factors from questionnaire}

As listed above, the main themes to emerge in relation to motivation to join, are that of pride, challenge and self-improvement. These themes emerged based on analysis of the responses given to the open questions, particularly question 21 and question 22, within the questionnaire and from data obtained from the focus groups. As motives they replicate one of the themes that emerged from the literature, relating to the national and international literature and the specific motives of pride, challenge and self- improvement (Clear 2017, Ginexi et al., 1995, Eighmey 2006). The following text extractions from the questionnaires, serve to highlight the nature of these responses across the three themes: "I wanted to serve my country and make my friends and family proud" (Q92) ${ }^{3}$. "I wanted to join, to be proud of myself and give my life more meaning" (Q12). "I joined the Defence Forces to serve Ireland" (Q55). "...I wanted to be physically and mentally challenged" (Q46). "I joined the Defence Forces because I wanted to be challenged, wanted to see if I was able to do it" (Q4). "I wanted to improve as a person and become as fit as possible" (Q17). "...because I wanted to better myself as an individual" (Q21).

As part of a separate question within the questionnaire that is, question 17, participants were asked to respond on a Likert scale to a number of proposed reasons for joining the DF. As will be explored individually overleaf, the vast majority, on average over 90 percent of participants 'strongly agreed' (green colour code) or 'agreed' (blue colour code) with three propositions for joining, mirroring the themes of pride, challenge and selfimprovement. This data is represented with the following pie charts.

\footnotetext{
${ }^{3} 123$ questionnaires were completed. They are numbered from Q1 to Q123. Throughout the paper particular extracts from these questionnaires are referred to as Q1, Q2...Q23...Q92 and so on for ease of reference for the researcher and reader.
} 


\section{I joined the DF to do something good and be proud of myself:}

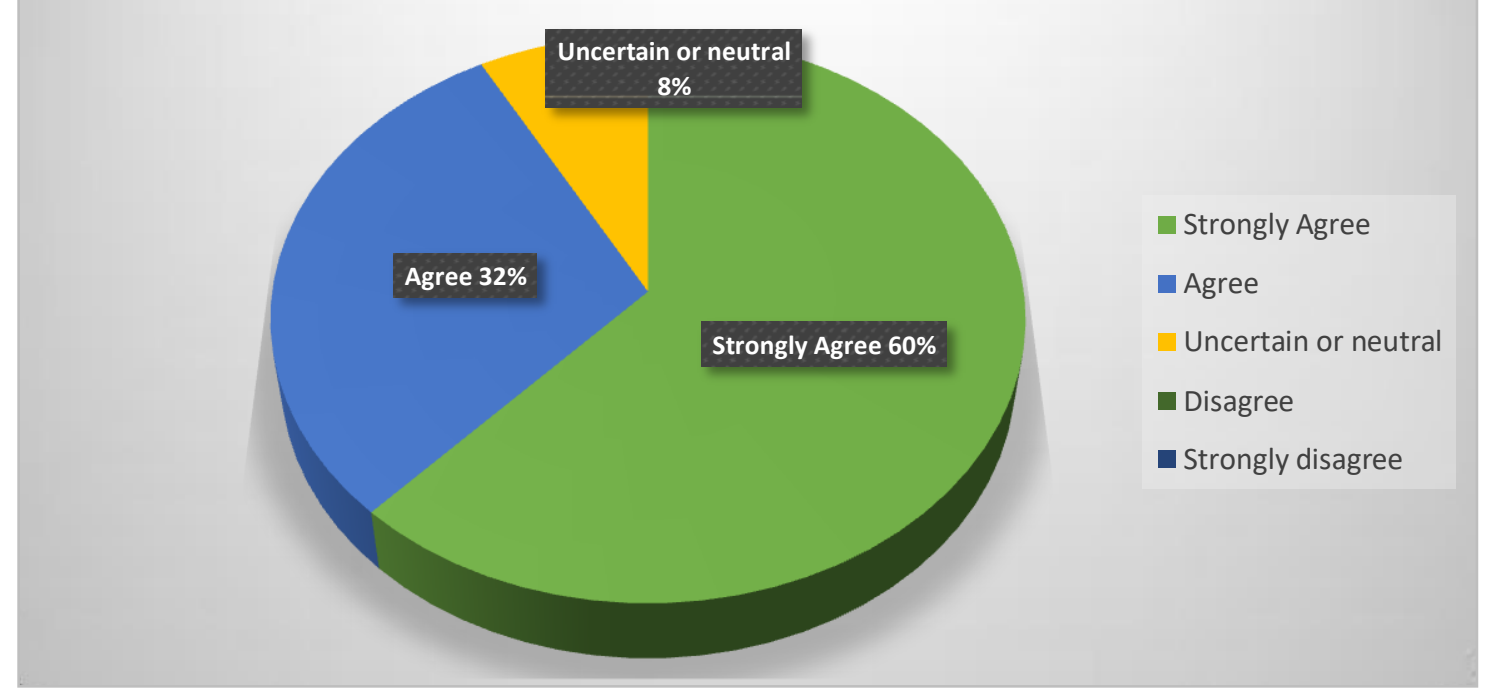

\section{Figure 3 : Motivation to join - Pride theme.}

Under the pride theme, (Figure 3) in terms of doing something good and being proud of oneself, 92 percent of participants either 'strongly agreed' or 'agreed', with eight percent 'uncertain or neutral'. This strongly intimates that pride is a key motivating factor for joining the DF. Low uncertainty (eight percent) and no disagreement among respondents reinforces this finding. 
Figure 4: Motivation to join - Challenge theme.

Under the challenge theme (Figure 4), there was a similar, high level of agreement, 59 percent 'strongly agreed' and 29 percent 'agreed'. Four percent of participants 'disagreed' and again

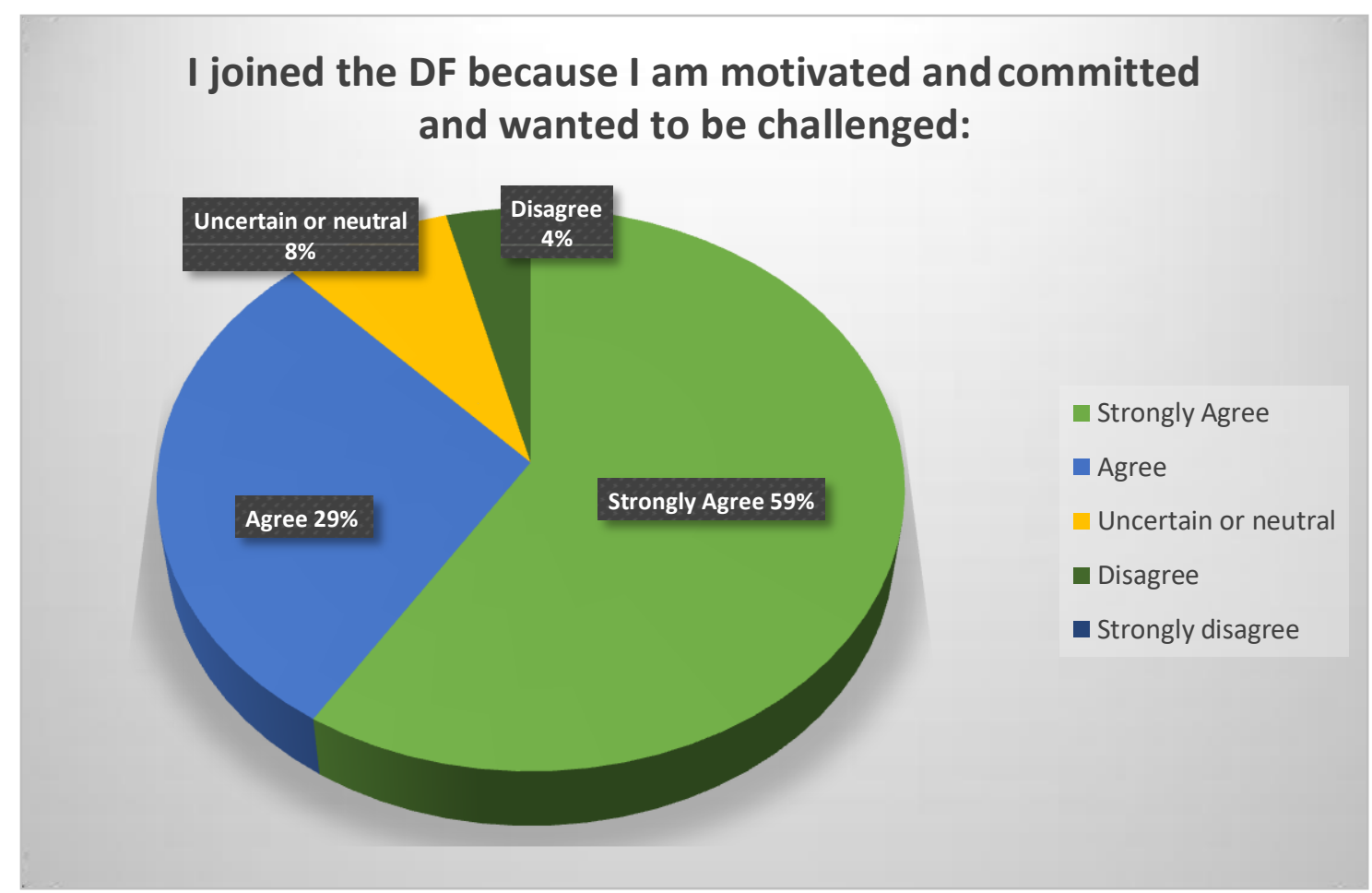

eight percent were 'uncertain or neutral'. This suggests that the challenge theme is to the forefront as one of the main factors for joining. However, this was the only theme of the three which had a disagreement response that is, four percent (dark green colour code). This may reflect the fact that certain personnel, although not a significant number, may not want to be challenged or may not be motivated or committed.

\section{I joined the DF to improve myself and make a difference:}

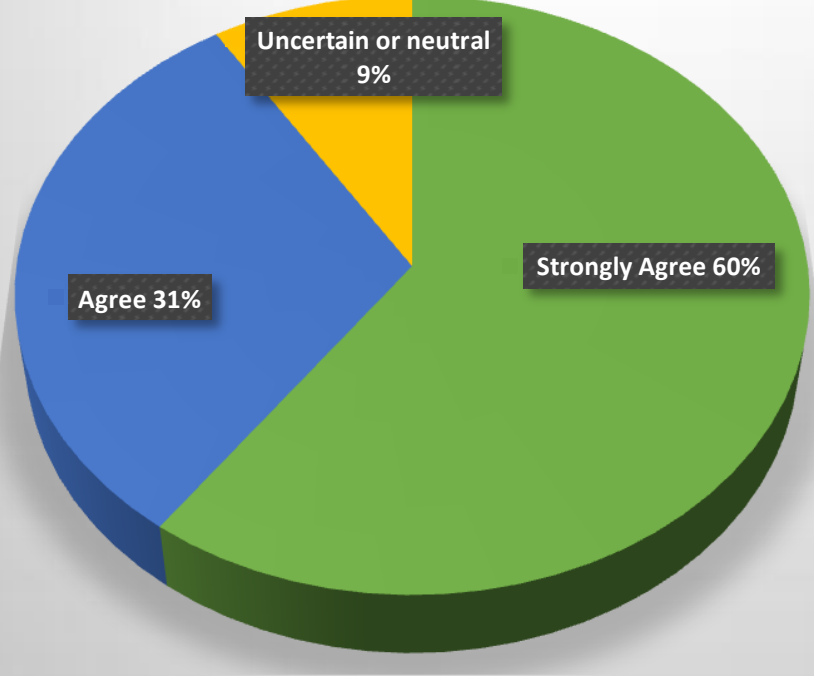

$$
\begin{aligned}
& \text { Strongly Agree } \\
& \text { Agree } \\
& \text { Uncertain or neutral } \\
& \text { Disagree } \\
& \text { - Strongly disagree }
\end{aligned}
$$


Figure 5: Motivation to join: Self-improvement theme.

Finally, within the self-improvement theme (Figure 5), 60 percent 'strongly agreed', 31 percent 'agreed' and nine percent were 'uncertain or neutral'. These findings certainly indicate that self-improvement and wanting to make a difference is a strong motivating factor for joining.

These three themes were the strongest factors to emerge. Other propositions within the questionnaire, which were identified as motivating factors for joining were: serving one's country, being part of a team, and gaining access to further training and education.

\section{Thematic analysis and exploration - Main factors from the focus groups}

Many of the sentiments expressed within the questionnaire were replicated further in the focus groups. The aspect of pride as a whole, when explored further, represented pride in different formats. For some, it represents self-pride, that is, pride in oneself for getting up and joining, getting through the challenge of training and doing something worthwhile. "Selfmotivation was important...I wanted to do something different" (FG2P1) ${ }^{4}$ and "...its pride as well...I wanted to show I could do it, I heard people say this fella hasn't got a chance...it's a feeling of self-pride" (FG1 P5). For others, it represents making people proud, that is, making family, friends and significant others proud, mirroring Eighmey's (2006) findings. "I was motivated to prove people wrong as I didn't do well in school, I wanted to do something to show them I was able to achieve" (FG2P4) and "I was getting in trouble and my parents were well respected so I wanted to do something to gain respect" (FG2P5), and also "...for me it was making my family proud. " (FG1P3). Finally, other participants represented this as national pride, that is, pride in the country, the flag, and the organisation. "...for me living up north, meant that wearing the Irish flag is a good feeling and gives a bit of pride...." (FG1P1) and "I wanted to join to go overseas and serve my country...that was part of it" (FG1P5).

\section{Challenge}

The challenge aspect represents that personal challenge to join, to get through the selection process, thereby gaining a sense of achievement at having done something worthwhile. This challenge concept was replicated within both focus groups. The television programme 'Recruits' 5 appeared to engender this sense of challenge for some. "I think the challenge of it was a big motivator for myself, hearing stories, watching the 'Recruits' programme...." (FG2P1). "...you can look at the things you have done and the challenges you get through...comradery and teamwork is a big thing" (FG2P6). As the participants were currently in training, there was a distinct sense of achievement and sense of satisfaction with having overcome the various challenges of recruit training. "You're able to look back at the challenges you get through...." (FG2P1). Of particular note, during the conduct of both focus groups, was the palpable anticipation of future challenges that remained, for both the individual and the

\footnotetext{
${ }^{4}$ Two focus groups were conducted. This abbreviation FG refers to either focus group 1 or 2 . P refers to participant and is numbered for ease of reference.

5 'Recruits' was the title of an RTE documentary that went behind the scenes to portray the day to day challenges of recruits in training in the Irish Defence Forces. The two-part show aired in Jul/Aug 2016.
} 
group: "...we still have hurdles to cross and things to get through, but we'll do it" (FG2P1). "There are opportunities...NCO courses, overseas, learning a trade, these are things we can look forward to." (FG1P2).

Other participants remarked on similar future challenges in the form of training courses, including for example, the Army Ranger Wing (ARW) selection course: "I will think about the ranger wing...maybe even an officer's course...." (FG1P6). It is also worth noting, that the researcher, experienced a strong sense of comradery, enthusiasm and group 'esprit de corps'. This was expressed through both body language and the openness and ease with which participants discussed their thoughts and feelings. The feeling of 'energy' in the room was particularly palpable during both focus groups, reflective of good relationships and high morale and was not something that the researcher had expected to experience, given the results of the recent DF Climate Survey. This survey, as cited in the introduction to this paper, highlights negative issues with terms and conditions, and suggests morale is low within the DF (McMahon et al., 2017).

\section{Self-improvement}

The theme of self-improvement refers to that aspect of developing oneself, partaking in education, learning new skills, and enhancing potential. One participant remarked that "being part of a team, learning new skills" was a distinct motivator (FG2P1), whereas another in the same group remarked that "the opportunities and educational options available within the Defence Forces" were motivators to join (FG2P7). The majority appeared enthused by these opportunities, however many were not aware of educational opportunities available prior to joining. When probed further by the researcher, it was clear that many participants were still not aware of these opportunities: "I hadn't realised that medical training was something you could get into in the army...." (FG2P7). In contrast, some participants felt that a focus on education and academia was not ideal, as they joined the DF to get away from education and an academic focus. One individual highlighted their dissatisfaction at having to do a series of essays as part of the early stages of recruit training: "I didn't join the army to do essays...." (FG1P5). On the whole though, participants recognised the value of training and upskilling in general and appeared to value the traditional benefits of becoming disciplined, organised and committed.

Some remarked that military training makes you attractive to civilian employers: "the training will even help you on the outside...you can say you were in the army...." (FG2P4). Particular areas of interest were driving courses and other areas such as a "trade" and "logistic experience" that not only would aid their development within the DF, but would also be transferrable, should the individual consider leaving the organisation in the future. Aspects of adventure training, such as parachuting and sea- diving were highlighted as particularly attractive and some participants were keen to pursue these skills further in their careers: "I like the adventure...the idea of jumping out of planes always got to me...." (FG1P5). The opportunity for career progression and development, in the form of moving up through the ranks and even progressing to become a commissioned officer was also discussed: ...maybe even an officer's course...." (FG1P6). 


\section{Thematic analysis - intrinsic or extrinsic motivation}

The findings above from both the questionnaire and the focus groups, reflect much of the academic research covered in the literature. The three main themes outlined in the paragraphs above, that is, pride, challenge and self-improvement, appear to suggest that quite a high level of intrinsic motivation exists in relation to general service recruitment within the Irish DF. This reflects one of the main themes emerging from the literature on motivational theory. Selfimprovement and personal pride when linked with self-esteem, reflect back to Maslow's (1943; cited by Taormina and Gao, 2013) hierarchy of needs. Herzberg's (1959; cited by Sachau, 2007) motivators, in terms of recognition, achievement, personal development and growth, certainly appear to be stronger motivators than other extrinsic or hygiene factors within this particular sample. Elements of self-determination theory are also evident from the data gained, both from the questionnaires and focus groups, that is, these participants want to find a role that they can do and that they can do well. Woodruff, et al., (2006) cited altruistic motives such as duty, self-improvement and personal discipline, while acquiring job skills, training and education, many of which are mirrored in the findings above.

A correlation also exists between these findings and that of previous gender specific studies done within the DF, cited earlier, where adventure, camaraderie, challenge, education and pride were all cited as motivating factors to join the DF. Armed with an understanding of these motivations and attractions, future DF marketing and advertising strategy can be moulded to capture the essence of these themes.

\section{Influencing factors}

The following section will explore factors influencing attraction to the DF. Figure 6 is based on the responses of all participants to question eleven of the questionnaire, where participants were asked to rank, from one to nine, the given influencing attraction factors in order of importance. The graph pictorially represents the number of times each factor was ranked between one and three. 


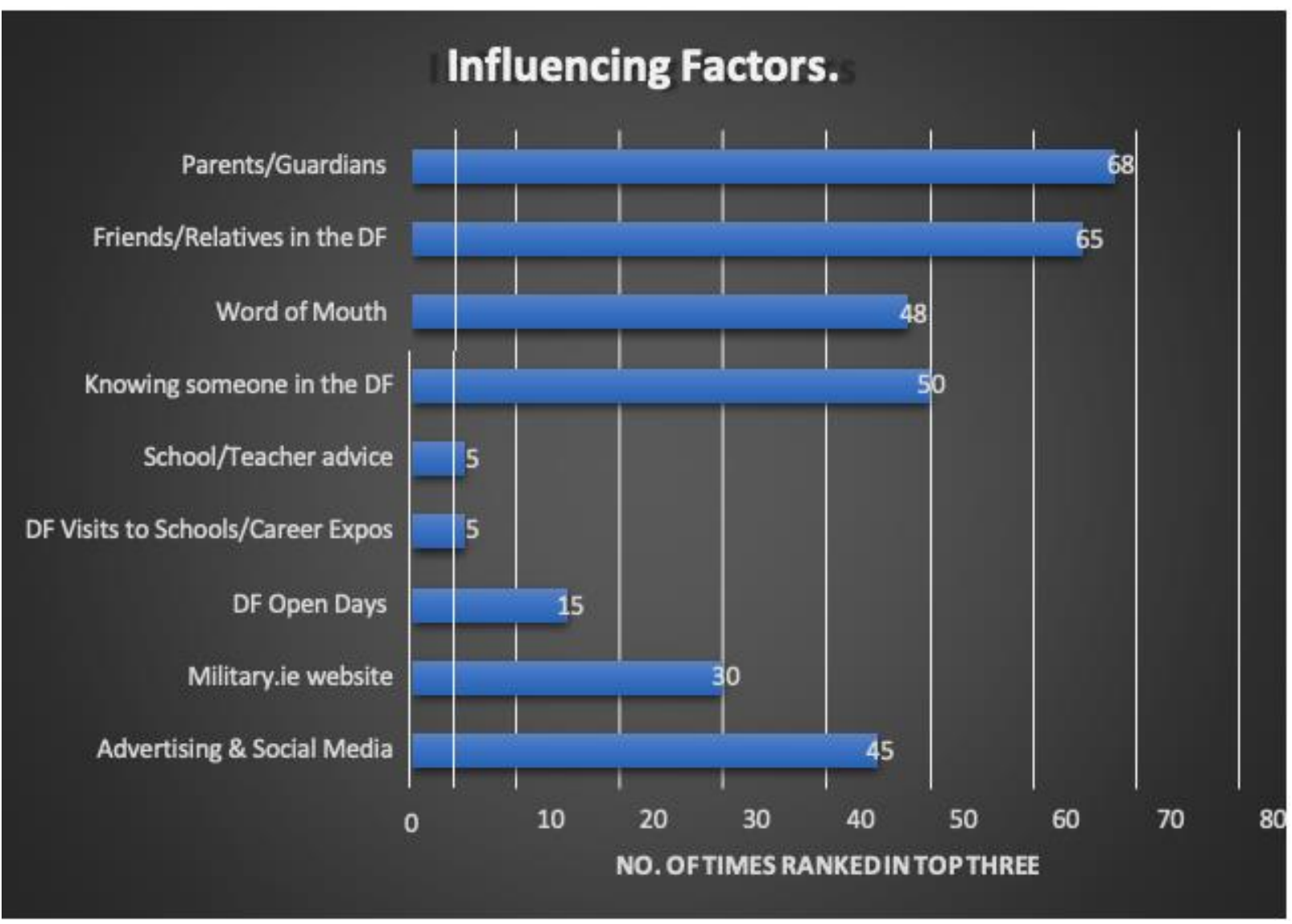

Figure 6: Influence attraction factors.

From the data, the strongest factors in terms of influencing attraction appear to be; 'parents/guardians' and having 'friends/relatives in the DF'. Other factors which were deemed important were; 'knowing someone in the DF', 'word of mouth', and 'advertising and social media'. These findings suggest that parents or guardians have a distinct influence on their children's career decision making process, which correlates with the 'gatekeeper' research earlier identified (TNS MRBI 2017; Egerton 2016; Clear 2017). Also suggested from these findings is the importance of current DF personnel in terms of recruitment. Having friends or relatives in the DF, or knowing someone in the DF, in addition to the general 'word of mouth' factor, all seem to have a strong, positive influence on attracting personnel to the DF. Advertising and social media, features as the fifth most important factor. As recent DF recruitment advertising campaigns are based predominately on social media, the researcher expected that this would be one of the most important influencing factors. Surprisingly this was not the case. On analysis, room exists for more research into the area of advertising and how influential it is in terms of recruitment, particularly considering the fact that is almost solely promulgated from the social media platform.

Conversely factors such as 'DF open days', 'school/teacher advice', 'DF visits to schools/career expositions' were not ranked as highly in terms of attraction influence. This finding suggests that these items were either not deemed as influential or important, or on the other hand, it may be reflective of the fact that there is not enough investment into these areas to raise their influence potential. This is significant considering the point made in the previous paragraph, concerning the influence of advertising. Further findings in relation to this and specifically career guidance teachers (CGT) and career expositions will be raised in the next paragraph. 


\section{Gatekeepers and Career Guidance Teachers (CGT)}

One of the themes to emerge from the literature, was the importance of gatekeepers in influencing a young person's career choice and specifically the military enlistment decision as part of that career choice. As outlined in the paragraph above, parents and guardians appear to be the strongest influencing factor in terms of attraction to the DF. This finding suggests that the gatekeeper role, remains critically important in terms of advertising, recruitment and influence. Teachers and specifically CGT are also cited as key gatekeepers in the literature (Sackett and Mavor, 2003; TNS MRBI, 2007; Egerton, 2016). Their impact, however, appears to be limited based on Figure 6 above. As proven influencers, this suggests that perhaps CGTs are not aware or are not prioritising DF careers. It also indicates that the DF could do more within teacher and CGT circles to highlight and publicise the many opportunities available within the DF.

As part of this research, two CGTs were interviewed. CGT1 ${ }^{6}$ remarked that she would normally recommend the military to "non-academic students" but would "warn" potential applicants about the "low pay". Both reflected that the military could do more to inform and interact with CGTs and both stated that it was only due to their own personal interest and initiative that they highlighted the DF as a career option. CGT2 stated that he felt he had limited information on military careers and believed information expositions to schools from serving military members would foster increased interest. CGT1 remarked that the DF has been surprisingly absent, from the Higher Options ${ }^{7}$ exhibition in the RDS: "Up until around 5 years ago the Defence Forces were present at the Higher Options in the RDS in September...having a presence there makes a huge difference and would definitely increase interest in a career in the DF" (CGT1). Both stated that there was interest in joining the DF among their students, while one indicated that there had been a distinct drop in CAO [university] applicants, suggesting that this is a market the DF could target: "...less and less students know what they want to do and this is reflecting the CAO drop, I am trying to highlight the other options available in the public service such as the DF" (CGT2). Both teachers proffered that the DF could interact more with the Institute of Guidance Counsellors (IGC) in terms of publicity. They both indicated that they retrieved DF information from the "military website" with CGT1 reflecting that she would prefer an additional "guidance type video".

\section{Sports and Fitness}

Ninety eight percent of respondents believed that maintaining a high level of physical fitness mattered to them. This does not immediately correlate with an interest in fitness but does suggest that all participants are aware of its importance and believe it is personally important. The role of sport and fitness was a theme arising from the literature review. One might expect that the majority of participants in the study, would be heavily involved in sports participation and teams, and would be involved in various clubs and societies. This did not prove to be the

\footnotetext{
${ }^{6}$ CGT1 refers to the first career guidance teacher interviewed. CGT2 refers to the second career guidance teacher interviewed.

7 "Higher Options" is a further education/career exposition where students are brought together with colleges and institutions to gain information on the range of courses and apprenticeships on offer.
} 
case, with less than half of the sample surveyed, participating in sports or sports teams, outside the DF environment.

This finding suggests that sport, is perhaps not as strong an influencer or attractor among recruit candidates. In contrast, interest in fitness and access to fitness facilities, did prove popular with the majority of participants in the sample. This interest in fitness corresponds with both national and international research, which relates to the physically active lifestyle in the military in general and to the attractiveness of fitness opportunities within the DF specifically.

\section{Discouraged from joining}

While answering question 14 of the questionnaire, 48 percent indicated that there were aspects which discouraged them from joining the DF. Of this 48 percent figure, 42 percent cited pay and conditions as the reason for this concern. This may be indicative of the negative publicity which exists in relation to pay and conditions in the DF (McMahon et al., 2017; Williams, 2017).

This aspect was replicated within the focus groups and will be explored further below. Other aspects to the career which were perceived as discouraging were; the "robust training environment", having to "deal with new people", and being "away from home regularly". Fourteen per cent of respondents stated that they were discouraged by a particular individual from joining the DF. Interestingly, of this sample, a number cited a CGT as the individual who discouraged. On a related but contrary line, in question 13, a minority, cited teachers and CGT, as influencers in shaping the decision to join. When this was cross checked against their addresses, the majority were from the Kildare region. This perhaps represents how well known the organisation is in the Kildare area, given the location of the military training base in the Curragh and the main administrative headquarters of the DF, in Newbridge, Co. Kildare. It may also reflect the possibility that in certain schools and with certain teachers and CGT, the DF is a higher priority and in better focus, than in other areas. Furthermore it suggests, in tandem with the considered findings in Figure 6 above, that CGT can have an impact both positively and negatively in influencing a person's career decision and moreover that the DF need to focus greater influence in this key area.

\section{Pay}

Directly related to extrinsic motivation and pay, the majority of the questionnaire participants, 62 percent, disagreed or strongly disagreed, with the fact that pay attracted them to the DF. This correlates with the 42 percent who cited pay and conditions as a concerning aspect prior to joining. This certainly suggests that personnel were aware of the pay implications prior to joining, yet still made the decision to join, strongly indicating that their motivations for joining are more intrinsic in nature. When concerns were expanded further within the focus groups, pay became a more emotive issue. "Pay was a big concern, people saying you can't get a mortgage...that was a big concern at the start...there's people cleaning toilets getting paid more than me..." (FG1P5). "...there are people transferring over to the guards because of the wages" (FG1P8). "I have friends who would join only for the money...the rent in Dublin is different than Donegal, but guys are still living with their family" (FG1P2). "The worst part of the whole thing is the pay...especially when you look at what we go through in recruit 
training...." (FG1P3). "My concern was the pay...trying to support someone as a single man it is ok, but you wouldn't want to be supporting anyone" (FG2P1).

These extracts highlight the genuine concerns that participants have over pay in the DF. Many expressed this aspect as one of the only negative aspects to life in the DF. There was also an understanding that overseas deployments in the future could serve to alleviate some financial concerns, but that these trips were perceived as being difficult to attain in the shortterm, due to the demand for positions.

\section{Recruitment Strategy and HR}

The discussion above dealt predominately with the findings arising from research conducted with new entrant recruits in training. The following paragraphs will illustrate the findings from interviews with a number of personnel in the DF HRM section and DF Public Relations (PR) branch, as well as discussion of findings presented from an international HRM academic, Professor Bert Schreurs (2018).

\section{Alignment of HRM practices}

A theme to emerge from the various interviews, was the many different HR strands and practices that are involved and exist within the recruitment process. As referred to by Schreurs (2018, March) "this alignment of the different HR practices is one of the most important principles" of recruitment. He quantifies this further by going on to say that: "one aspect or practice cannot exist in isolation and all [practices] must align with the vision of the organisation...." Within the DF, this alignment exists and works harmoniously, however excluding the DF White Paper (2015) document, there is no specific written guidance document or policy, formalising and outlining this relationship and strategy. This appears to be a significant gap within the DF recruitment framework.

As part of the White Paper, the Minister of Defence sets the target of maintaining the DF's strength of 9,500 personnel. As referred to by Hanly (2018, April), Deputy Director HRM (DDHRM), this is the basis of DF recruitment policy, "it's where you have to start off, our intent is to get to 9,500". The DF PR section's role within recruitment, as alluded to by O'Connor (2018, April), DF Press Officer, is to "design and come up with the recruitment campaign". The DF competitions officer, Lafferty (2018, April), manages the process, including applications and selection and her role involves "running and managing all the competitions". Input from HRM in terms of vacancies and campaign design is regular and happens across all levels. The DF organisational psychologist, Connolly (2018, April), has input into selection procedures and standards. Overall, the process is streamlined and effective, however it is dependent it appears, on the professionalism, experience, teamwork and understanding of the many individuals involved. All DF interviewees acknowledged that an information gap exists in relation to what the current motivating factors leading to general service recruitment are and why people want to join the DF.

When the interviewees were asked for their own personal views on what motivates people to join, a range of topics were advanced. These included the following opinions: "people join for adventure and challenge" (Hanly 2018), "a sense of wanting to serve" (Lafferty 
2018), "the experiential aspect" (Connolly 2018), and that they "want a job with meaning and a sense of purpose" (O'Connor 2018). This highlights the diversity of opinion present in relation to motives to join. It could be argued that these opinions broadly correlate with the questionnaire and focus group findings and could be loosely categorised under the themes of pride, challenge and self-improvement. It does highlight, however, the lack of clear understanding in relation to why people are joining the DF at general service level.

\section{Identifying a target market}

It could be supposed that perhaps a specific sector, for example team sports players can be exploited. When this concept of a target market was put to Schreurs, he underlined that identifying such a target market, is perhaps the greatest difficulty that exists in military recruitment. "This is difficult for the military as there are many different facets...different to other companies it is very difficult to identify the target population...." This is echoed and perhaps challenged by Hanly (2018), who states that the DF require a diverse population rather than a particular target stream within that population:

I think the strength of the DF is the diversity element...we not only need sports persons we need the technical guy, the debater etc...we need that diversity in character...we have a multiplicity of roles so you need a wide demographic to choose from which should mirror society.

The importance of this diversity of recruitment was reiterated by the other DF interviewees and remains a strong aspect of DF recruitment.

\section{What does success look like?}

One of the interesting aspects emerging from the findings is the question of what success looks like. Schreurs (2018) believes that an organisation needs to define what success looks like. In his belief, successful recruitment occurs when personnel are attracted, selected and then hired into an organisation, perform well in training and are effective and durable in their role within the organisation. This can only be defined with examination of a candidate's progression and a resultant refinement of the recruitment process which he referred to as "a feedback loop" and is shown as part of his recruitment model, Figure 7 overleaf: 


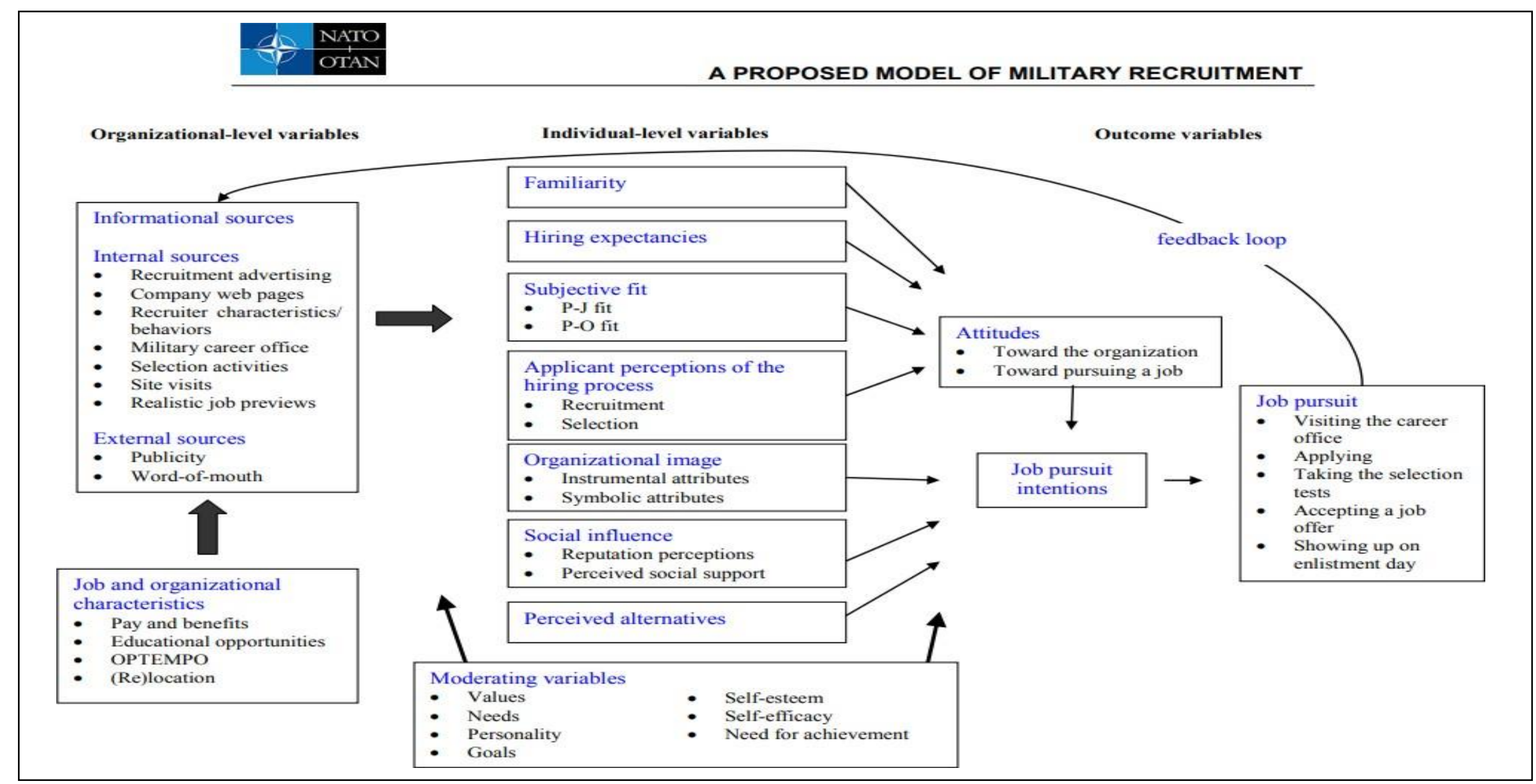

Figure 7: Proposed model of military recruitment (Schreurs and Sayed 2007, cited in Research Task Group, HFM-10, North Atlantic Treaty Organisation (NATO), 2007) 
As can be seen from this model there are many influencing factors and variables contained within. The model has three distinct groups or pillars; organisational, personal and outcome variables. Schreurs has argued that the feedback loop should and would progress further than enlistment day and he suggests feedback should be reflected on throughout training and into the early stages of the candidates' career. In his opinion, with this full picture, success in recruitment can then be measured and defined.

This concept of defining success is particularly interesting. All DF stakeholders within the recruitment process have particular roles and aims. Achievement of these aims can be defined as success. On reflection, even though there is general alignment, the individual stakeholder's recruitment aims are each subtly different. For DF PR section, the aim is "to capture people's attention and get them to apply". Achievement of this, through successful advertising campaigns is defined as success for this stakeholder. For DF HRM, the aim it could be postulated, is to recruit a diverse population segment, to achieve and maintain a strength of 9,500 personnel. For competitions' section, the aim is to manage an effective competition and selection process, to achieve a defined target number, within the eligibility criteria allowed. For the DF psychologist, the aim is to assess and set sufficient standards to maintain the quality of recruit required. All stakeholders, have subtly different aims and as such, different definitions of success. The concept of a feedback loop to understand who we are recruiting, who are performing best and what that entails for our recruitment process is not something that is carried out within the DF recruitment process at present. It does however warrant consideration.

\section{Recruit Quality}

A sub theme to emerge from the earlier examined literature is that as military recruitment becomes increasingly challenged as a result of a number of factors, including improved national economies and employment rates, recruit quality may be affected. The Irish DF is not exempt from this challenge. Connolly (2018) cited that annually there is "a debate between numbers and the standard required". As the demand to recruit more numbers increases, the standard he believes, is in danger of decreasing. This is not aided by the currently high employment rate in Ireland. Connolly, believes the maintenance of a psychometric test, set at a sufficient minimum achievement mark, is critical to maintaining a high standard of individual entering the DF. He references other militaries that have reduced their selection standards in an attempt to recruit more individuals. He cites the problems that this has caused in relation to the quality of the average soldier and how this has created legacy issues for the organisation, in terms of training and performance. Interestingly he agrees with Schreurs' ideas, and would be eager to develop research, particularly in relation to the 'feedback loop', but cites a distinct lack of resources within HR in the DF. According to Connolly, little data is stored on recruit demographics and insufficient comparable data is stored in order to assess fluctuations in terms of standards or trends in applications. Even if it was, resources to assess and analyse this data are not available.

By exploring the experience of new entrants to the DF, a person's underlying motivation to join the DF as a general service recruit is now somewhat clearer. This motivation appears to be intrinsically formed and centres on pride, challenge and self-improvement. The factors that influenced that decision to join are also more tangible and revolve around personal relationships with others in the DF and on the influence of parents and other gatekeepers. The overarching DF recruitment strategy and policy was examined and reflects the various factors and HR branches involved within the recruitment process. Challenges such as who the DF are targeting, what is 
successful recruiting and the future challenges that exist in relation to quantity versus quality have emerged.

\section{PART 4. Conclusions and Recommendations.}

The aim of this paper was to explore a person's underlying motivation to join the DF as a general service recruit and to identify the primary factors influencing the decision to join. In essence, the aim was to ascertain why people join the DF. A secondary aim of the research, was to examine the overarching DF recruitment strategy and policy.

\section{Key Findings and Conclusions}

\section{Understanding the motivation to join}

A primary aspect of the research was to explore and examine the underlying motivations to join the Irish DF as a general service recruit. As was expected, based on the academic evidence presented within the existing literature, these motivations are wide-ranging, varied and personality dependant. However, three distinct themes emerged as pillars for understanding the motivation to join. These themes were pride, challenge and self- improvement. This key finding correlates with the literature suggesting that personnel recruited to the Irish DF are more intrinsically motivated than extrinsically motivated. This finding suggests that the framework for future DF advertising could be constructed on these pillars.

\section{Factors influencing the decision to join}

A number of influencing factors were identified. Key among these factors were; the role of 'gatekeepers', the influence of current DF members, in terms of their positive connections with potential applicants, and the importance of 'word of mouth' in terms of DF perception. As was posited within the literature, 'gatekeepers' are deemed particularly important in influencing one's career path decision. Parents, career guidance teachers (CGT) and other role models are often cited as being key gatekeepers (TNS MRBI, 2007; Egerton 2016). Their importance is significant within the recruitment process as a whole. Central to the findings within this area, is the perceived limited impact CGT are having on young personnel joining the DF given their potential as influencers. A distinct, unexpected finding of the research, was the significantly low recruitment rate directly from school, which was found to be only four percent of study participants. This, coupled with the limited influence of CGT, suggests an area worthy of further exploration and possible exploitation by DF recruitment personnel. A separate but related factor concerns advertising and social media, which was ranked as the fifth strongest influencing factor from the nine options provided. The advertising strategy for DF recruitment is directed almost predominately across social media platforms but it may not be having the requisite influence as previously believed.

Sport was proposed as a likely influencing factor. This did not transpire to be the case, as less than half of personnel surveyed participated in sport. Fitness and access to fitness facilities however were cited influencing factors.

Pay was the main negative aspect and concern for personnel considering joining the DF. Just under half of all personnel surveyed, cited pay as a concern prior to joining. Despite this, these 
personnel joined in any case, correlative somewhat with intrinsic motivation foundations explained earlier. Within focus group discussion, the aspect of pay was emotive and was cited as being one of the only negatives to life in the DF.

\section{DF Recruitment Strategy and Policy}

DF recruitment strategy and policy is primarily based on information from the DF White Paper (2015). Strategy is driven by the HRM demand and numbers required and an advertising campaign is mapped in parallel with this demand. Policy is implemented in terms of diversity and gender targets, minimum standard requirements, and a comprehensive selection process. However, although all aspects of the HRM process are highly functioning and aligned, no definitive overarching guidance documentation exists. An important aspect of recruitment as alluded to by Schreurs (2018) is defining success. Success in terms of DF recruitment is focussed squarely on numbers, with little concern it seems for performance and quality following induction. This in tandem with a lack of resources, a lack of data and specialised analysis and finally the absence of any 'feedback loop' to examine the validity of the process, inhibits the overall success of the recruitment process.

\section{Recommendations}

A number of recommendations emanate from this paper. The following are those that are deemed most critical and are listed in order of priority:

1. Dedicate sufficient resources to DF recruitment. Rather than focussing the vast majority of resources into a social media centred recruitment strategy, the research illustrates the vital role that gatekeepers such as parents play in influencing military career decision making. Gatekeepers need to be specifically targeted and included in the recruitment process. Furthermore, deployment of dedicated DF recruitment teams to target schools in coordination with CGTs, to increase the number of school-leavers applying for the DF is also warranted. This team should have an expertly designed message capturing the important influencing factors as highlighted in this study.

2. Generate an overarching DF recruitment policy guidance document. This document should include a recruitment model and strategy and should aim to align the various HRM functions within recruitment as well as creating a provision for further DF recruitment resources, helping alleviate the gaps identified by the research. These resources should include dedicated data management specialists and analysts, specialised recruitment personnel and employment of HR practitioners to conduct recruitment validity studies as part of an overall 'feedback loop'. These added resources would significantly aid defining, measuring and ultimately achieving success in DF recruitment. 
3. Incorporate the themes underpinning motivation to join, into the DF recruitment process particularly in terms of advertising, information and education. Ensure that these motivations are regularly assessed into the future. By understanding the motivations behind why people join, advertising and the recruitment campaign process as a whole will be more successful, encouraging more of the 'right' people to be recruited for the 'right' reasons.

\section{Conclusion}

The challenges of effective military recruitment are not unique to the Irish DF. Many larger militaries continue to struggle to sufficiently recruit personnel. The most recent DF recruitment campaign, launched in February 2018, is already witnessing a reduction in applicants (Lafferty 2018). This situation will likely deteriorate further in the future, if sufficient resources are not implemented. Rather than reacting, the DF should be proactive in this area, to ensure sufficient personnel in terms of quantity and quality continue to be recruited into the Irish DF. At the foundation of this process is an understanding of the motivation behind the application to join. This paper now provides further understanding of this motivation and should be used to refine the recruitment process. Further findings from this paper in relation to policy development and improvement, investment in resources, both data and analytical, and recommendations for process analysis in terms of defining overall success are valuable. These findings and recommendations should serve to assist DF HRM policy makers to incorporate more effective policies and practices into the future.

Please note that the views expressed in this article are those of the author alone and should not be taken to represent the views of the Irish Defence Forces, the Command and Staff School or any other group or organisation. 


\section{BIBLIOGRAPHY}

Armour, K. and McDonald, D. (2012) Research methods in Physical Education and youth sport. New York: Routledge.

Armstrong, M. (2012) Armstrong's Handbook of Human Resource Management Practice (12th ed.). London: Koganpage.

Asch, B.; Du, C.; Schonlau, M. (2004) Policy Options for Military Recruiting in the College Market Results from a National Survey. California: RAND Corporation.

Bachman, J. G., Segal, D. R., Freedman-Doan, P., and O'Malley, P. M. (2000) Who chooses military service? Correlates of propensity and enlistment in the US Armed Forces. Military Psychology, 12(1), 1-30.

Bevan, M. (2014) A method of phenomenological interviewing. Qualitative Health Research, 24(1), 136-144.

Bogdan, R., and Biklen, S. K. (2003) Qualitative research for education: An introduction to theory and methods (4th ed.). Boston: Allyn and Bacon.

Brown, and Duane. (2002) Career choice and development. San Francisco: Jossey-Bass business and management series.

Bryman, A. (2008) Social Research Methods. New York: Oxford.

Bryman, A. and Bell, E. (2007) Business Research Methods. Oxford: Oxford University Press.

Buehring, A., Cassell, C., Johnson, P., Symon, G., and Ebrary, I. (2006) Qualitative methods in management research. Bradford, England: Emerald Group Publishing.

Chartered Institute of Internal Auditors. (2018) Recruitment. Retrieved from CIPD: https://www.cipd.co.uk [accessed 04 Feb 2018].

Chartered Institute of Personnel and Development. (2017) CIPD recruitment. Retrieved from CIPD: https://www.cipd.co.uk [accessed 04 Jan 2018].

Clear, O. (2017) Why Women Join: A perspective on gender and the Irish Defence Forces. Unpublished MA Thesis. University of Maynooth.

Cohen, L., Mannion, L., and Morrison, K. (2011) Research methods in education (7th ed.). Oxxon: Routledge.

Cresswell, J. W. (2003) Qualitative, quantitative and mixed method approaches (2nd ed.). London: Sage Publications.

Deci, E. L., and Ryan, R. M. (2000) The "What" and "Why" of Goal Pursuits: Human Needs and the Self-Determination of Behavior. Psychological Inquiry, 11(4), 227-268.

Defence Forces Ireland. (2016a) Defence Forces Leadership Doctrine. Dublin: Defence Forces Printing Press.

Defence Forces Ireland. (2016b) Defence Forces Annual Report. Dublin: Department of Defence. 
Defence Forces Ireland. (2017) Army Induction. Retrieved from Defence Forces Ireland: www.military.ie [accessed 22 Dec 2017].

Department of Defence. (2015) Defence Forces White Paper. Dublin: Óglaigh Na hÉireann, Defence Forces Printing Press.

Egerton, G. (2016) The Use of Social Media for Targeted Recruitment of Females to the Irish Defence Forces. Unpublished MA Dublin City University.

Eighmey, J. (2006) Why do youth enlist? Identification of underlying themes. Armed Forces and Society, 32(2), 307-328.

Ginexi, E. M., Miller, A. E., and Tarver, S. M. (1995) A Qualitative Evaluation of Reasons for Enlisting in the Military. Interviews with New Active-Duty Recruits. Available https://www.researchgate.net/publication/235039259 A Qualitative Evaluation of Reas ons for Enlisting in the Military Interviews with New Active-Duty Recruits [accessed 03 January 2018].

Gottfredson, L. S. (1981) Circumscription and compromise: A developmental theory of occupational aspirations. Journal of Counselling Psychology, 545-579.

Johnson, R. B., and Onwuegbuzie, A. J. (2004) Mixed Methods Research: A research paradigm whose time has come. Educational Researcher, 33(7), 14-26.

Knowles, J. A., Parlier, G. H., Hoscheit, G. C., Ayer, R., Lyman, K., and Fancher, R. (2002)

Reinventing army recruiting. Interfaces, 32(1), 78-92. Retrieved from

https://doi.org/10.1287/inte.32.1.78.17 [accessed 04 January 2018].

Lester, S. (1999) An introduction to phenomenological research. Stan Lester Developments. Taunton, Taunton, UK: Stan Lester Developments. Retrieved from www.sld.demon.co.uk/resmethy.pdf [accessed 06 January 2018].

Lincoln, Y. (2010) What a long, strange trip it's been: Twenty-five years of qualitative and new paradigm research. Qualitative Inquiry, 16(6), 3-9.

Marchington, M., Wilkinson, A., Donnelly, R., and Kynighou, A. (2016) Human Resource Management at Work (6th ed.). London: Chartered Institute of Personnel and Development.

Maynooth University. (2016) Maynooth University Research Ethics Policy. Available https://www.maynoothuniversity.ie/research/research-development-office/ethics/ethicsgeneral-policy-documents [accessed 30 May 2018].

McMahon, J., Mac Curtain, S., and Harnett, C. (2017) Workplace Climate in the Defence Forces Phase 2: Results of the Focus Group Research. Limerick: University of Limerick.

Mitchell, T. R. (1982) Motivation: New Direction for Theory, Research, and Practice.

The Academy of Management Review, 7(1).

Opie, C. (2004) Doing educational research. London: Sage Publications.

Patton, M. (2001) Qualitative research and evaluation methods (2nd ed.). Thousand Oaks; California: Sage Publications. 
Philips, J. A. (2015) Military Enlistment: The Motivations of Former Military Personnel Coming from Single Parent Homes. Walden University. Retrieved from https://search- proquestcom.jproxy.nuim.ie/docview/1694579821?pqrigsite=summon\&https://search.proquest.com/pqdtglobal [accessed 05 January 2018].

Pilske, R. M., Ellg, T. W., and Johnson, R. M. (1986) Towards an Understanding of Army Enlistment Motivation Patters. Alexandria VA: US Army Research Institute for the Behavioral and Social Sciences.

Rashimi, T. K. (2010) Recruitment Management. Bengaluru: Himalaya Publishing House.

Research Task Group HFM-10. (2007) Recruiting and Retention of Military Personnel (Recrutement et rétention du personnel militaire). Research And Technology Organisation, NATO. (Vol. 323).

Ryan, R., and Deci, E. (2000a) Self-determination theory and the facilitation of intrinsic motivation. American Psychologist, 55(1), 68-78.

Ryan, R., and Deci, E. (2000b) Intrinsic and Extrinsic Motivations: Classic Definitions and New Directions. Contemporary Educational Psychology, 54-67.

Rynes, S. L., Bretz, R. D., and Gerhart, B. (1991) The importance of recruitment in job choice: A different way of looking. Personnel Psychology, 44, 487-521.

Sachau, D. A. (2007) Resurrecting the motivation-hygiene theory: Herzberg and the positive psychology movement. Human Resource Development Review, 6(4), 377-393.

Sackett, P., and Mavor, A. (2003) Attitudes, Aptitudes and Aspirations of American Youth: Implications for Miilitary Recruiting. Washington DC: National Academies Press.

Saks, A. M. (2005) The Impracticality of Recruitment Research. In A. Evers, N. Anderson, and O. Voskuijl, The Blackwell Handbook of Personnel Selection (pp. 47-72). Malden: Blackwell.

Sarantakos, S. (2005) Social Research (3rd ed.). New York: Palgrave Macmillan.

Segal, D. R., and Segal, M. W. (2004) America's Military Population. Population Bulletin (English Edition), 59(4).

Sheldon, K. M., Williams, G., and Joiner, T. (2003) Self-Determination Theory in the Clinic : Motivating Physical and Mental Health. Yale: Yale University Press.

Silverman, D. (2013) Doing qualitative research: A practical handbook (4th ed.). London: SAGE.

Smith, M., and Heinecken, L. (2014) Factors influencing military recruitment in South Africa: the voices of Cape Town high school learners. African Security Review, 23(2), pp. 102-116.

Sparrow, P., and Makram, H. (2015) What is the value of talent management? : building valuedriven processes with a talent management architecture. Human Resource Management Review, 25(3) 249-253.

Taormina, R. J., and Gao, J. H. (2013) Maslow and the Motivation Hierarchy: Measuring Satisfaction of the Needs. American Journal of Psychology, 126(2), 155-177.

Taylor, J. K., Clerkin, R. M., Ngaruiya, K. M., and Velez, A.-L. K. (2015) An Exploratory Study of Public Service Motivation and the Institutional- Occupational Model of the Military. Armed Forces and Society, 41(1), 142-162.

TNS MRBI. (2007) Retention and Recruitment of Women in the Defence Forces. Dublin: TNS MRBI. 
Torrington, D., Hall, L., and Taylor, S. (2005) Human Resource Management (6th ed.). Essex, England: Prentice Hall.

Tyson, S., and York, A. (2000) Essentials of HRM. Oxford: Butterworth-Heinemann Ltd.

Vroom, V. H. (1966) Organisational Choice: A study of pre and post decision processes. Organisational Behaviour and Human Performance, 212-225.

Walsh, T., and Ryan, A. (2015) Writing your thesis: A guide for postgraduate students. Maynooth: Mace Press.

Weightman, J. (2004) Managing People. London: Chartered Institute of Personnel and Development. Williams, P. (2017) Recruits applying to Forces to protect benefits. Irish Independent Newspapers, 31 October, 5. Dublin, Ireland: Independent Newspapers.

Woodruff, T., Kelty , R., and Segal , D. R. (2006) Propensity to Serve and Motivation to Enlist among American Combat Soldiers. Armed Forces and Society, 32(3), 353-366.

Yin, R. (2009). Doing Case Study Research (4th ed.). Thousand Oaks; California: Sage Publicatons. 